\title{
Analysis of Industrial Heritage Protection and Utilization Development Mode under the Background of Urban Renewal-- Taking Changchun Tractor Manufactory as an Example
}

\author{
Shuai Yang 1, 2, a, Yao $\mathrm{Wu}^{2, \mathrm{~b}}$ \\ 1Zhuhai College of Jilin University, Zhuhai 519041, China; \\ ${ }^{2}$ Faculty of Innovation and Design, City University of Macau, Macau, China. \\ aU17092105159@cityu.mo, byaowu@cityu.mo
}

\begin{abstract}
There are many remains for China's industrial buildings, protecting some and giving new connotations is meaningful to explore the protection and recycle mode of industrial heritages, and realize the sustainable development of industrial heritages. This is also a next growth point of urban renewal for urban development; the areas that have not adapted to the development of modern urban society are reconstructed, including old industrial areas, old residential areas, etc., all are comprehensively renovated, functionally changed or completely dismantled and reconstructed, and industrial heritages left over from history are renewal emphasis. This paper discusses the overall development objectives of urban renewal, and elaborates with the culture and economy two major development objectives; the protection and utilization mode is also analyzed for Changchun Tractor Manufactory, the protection and utilization principle is analyzed according to circumstances for Changchun Tractor Manufactory, the special value of industrial buildings in Changchun Tractor Manufactory is preserved; five major development modes are used to demonstrate, examples are given for analysis and summary, respectively, and find out the development mode of industrial heritage suitable for Changchun Tractor Manufactory.
\end{abstract}

Keywords: Urban renewal; industrial heritage; protection and utilization; development mode.

\section{Urban Renewal and Industrial Heritage}

The old industrial base in the northeast, along with the economic and social development and transformation, many major industrial projects have ended their historical mission. Nowadays, the old industrial areas in a large number of cities are gradually declining and falling into disuse. The protection of existing industrial heritages is still insufficient, and we have the responsibility to make them play their unique cultural and economic value under the background of urban renewal.

\subsection{Cultural Value}

Industrial heritages bear the important connotation of industrial civilization and industrial culture, which are also important parts of human history and culture, and they are historical relics of industrial society. The value of industrial culture is reflected in its unique aesthetic value, at present, people also realize that the protection of industrial heritages is also to protect the whole process of human development. Maintain cultural creativity and diversity. Most of the production facilities, construction space are much different from agricultural society mode in the industrialization process, the structures of the space are generally spacious and bright, and the equipment is complex and diverse, which can reflect the design sense of space and product design. Factory in the industrial age likes a small society, which also contains complex social relationship. The industrial heritages under industrial activities have had a profound impact on today's society, such as the unreasonable protection of industrial heritage, which will lose the most important memory of the city. Based on this, providing more urban cultural connotations will enrich the history of the whole city, all activities that have experienced urban industry will be re-recorded, and it will have far-reaching significance for human history. 


\subsection{Economic Value}

The economic value of industrial heritages is reflected in the economic benefits which can bring to people. In the factory's districts formed by industrial heritages, warehouses, houses, supporting facilities, etc. can be used for other purposes, and bring new economic growth points. Large-scale factory's districts can also be effectively protected and developed into unique cultural and business parks. Due to the unique cultural attributes, the economic value of industrial heritage is not only realized through imitation, it must find characteristic model corresponding to its attributes to renew, the industrial landscapes formed by industrial heritages are irreproducible, multiple values and attributes are accompanied by the unique economic and individualized urban appearances formed by the protection of industrial heritages, which will change the problem of urban similarity. The economic value of industrial heritage can also increase the continuity of regional vitality and provide new vitality for declining urban areas, including providing long-term stable employment opportunities for community residents and space and resources for urban tourism and commercial development. This unique economic value is fundamentally different from ordinary real estate development.

Looking for the rich historical accumulation of the city, providing new ideas for the renewal of the city, providing new vitality for the development of the city, retaining the material form formed by the industrial heritages, inheriting and developing the special cultural spirit in the industrial heritages, these are not just the history of industrial civilization, what's more, bring more possibilities for the development of the city's economy. Therefore, the protection and utilization of industrial heritage has been regarded as the important pillar of social and economic development, people must fully realize the important value that industrial heritage can give to society, regard it as a valuable social wealth, and constantly exploring and meeting social needs is the only way to protect industrial heritage.

\section{Protection and Utilization of Changchun Tractor Manufactory}

In order to meet the demand of industrialization construction after the founding of People's Republic of China, Changchun Tractor Manufactory was set up under the guidance of giving priority to the of heavy industry development. In 1950s, China's tractor manufactories were represented by Luoyang Tractor Factory in Luoyang City, Henan Province and Changchun Tractor Factory in Changchun City, Jilin Province.

Luoyang Tractor Factory was established on October 1, 1955 in Luoyang City, Henan Province, Changchun Tractor Factory was set up in 1958 and became the largest wheel tractor production base in China, It is second largest agricultural machinery manufactory, which rank second only to Luoyang First Tractor Factory. These two tractor manufactories are national key planning projects and almost built at the same time; which has made great contributions to the development of agricultural mechanization in China. However, since the beginning of the 21 st century, with the establishment of the socialist market economic system, the fate of these two enterprises is completely different. Luoyang Tractor Manufactory is still in production and use, but Changchun Tractor Manufactory stopped production and closed down in 2002. For the industrial heritages of Changchun Tractor Manufactory, how we protect it, how to let it continue its value, how to make our collective memory last longer, it is undoubtedly a very significant and important issue we face.

\section{Preserving the Special Value of Industrial Buildings in Changchun Tractor Manufactory}

The rapid development of the economy has brought about a great step in the whole social environment; the development of cultural forms has also shown a trend of keeping pace with the times in this tide, especially becomes globalized and diversified. Industrial civilization, as an important part of the development of global civilization, its power is immeasurable. Since the British Industrial Revolution in the eighteenth century, industrial culture has greatly promoted the production of big machine; however, man as a part of the main body, create innumerable admirable industrials cultures 
with powerful wisdom. Throughout the ancient buildings carrying historical culture, all of them have evolved into gems with great industrial civilization over time. Especially for the materials of the building, the craft of construction, etc., people witness their vicissitude and sense of honor. The industrial buildings of Changchun Tractor Manufactory, as the intangible cultural level in industrial culture, have the characteristics of old industrial buildings, how many years of glory, how many years of vicissitudes, every painting of the wall, every scratch on the ground and footprints left by the walk year by year, everywhere is a witness of history, and all are glory that once existed. The promotion of time and space makes the accumulation of industrial culture not only manifest in architecture, but also subtly affects the people living in this hot land, their daily behavior habits, moral cultivation, life customs and pursuit of the spiritual world follow characteristics of individual socialization, and continuous evolution of the particularity in the industrial age. The unique space structure and building materials of Changchun Tractor Manufactory have made this building to be a landmark building nearly, the inheritance of memory bears the longtime spirit of the people of Changchun, which occupy an important position in the minds of the people of Changchun, this deep emotion like the rich feelings and awe of Zhuhai people to the fisherwoman, the Changchun Tractor Manufactory used to be the pride of Changchun, and now and future must be, the traces of its survival have made past industrial spirit and culture to be passed down and carried forward. At present, the protection of the old buildings has become very meaningful; these buildings fully taps the memory of the society and closely links the emotional sustenance with the protection of industrial culture, the existence of Changchun Tractor Manufactory make the city exude unique artistic charm and evokes People's feelings to the city.

\section{Analysis of Protection and Utilization Mode of Industrial Buildings in Changchun Tractor Manufactory}

\subsection{Industrial Museum Mode}

One industrial museum is constructed on the former address, and expected to transform the original factory into industrial museum. According to foreign cases, many industrial buildings have been successfully converted into museums for us to study and consult. For example, the Los Angeles Modern Museum was reconstructed from a warehouse. The museum was built from an empty warehouse with only one frame left, covered 5,760 square meters, located in the prosperous downtown of Los Angeles, after reconstruction, the original features of the old building can be seen, renovation and reinforcement, add service facilities, including ramps for disabled people. Stream sand blast is used for cleaning racks, ceilings, floors and museum in roofs. The only obvious change in the building is the addition of an external glass canopy to highlight the identity of the museum. The reconstruction of the temporary contemporary museum has achieved great success, which make the people of Los Angeles realize the dual value of industrial heritage and the environment.

\subsection{Commercial Building Mode}

Large-span factory buildings are reconstructed into shopping malls, supermarkets, stadiums or theaters, during the reconstruction process of domestic industrial parks, many large public buildings have established cultural creation parks and commercial complexes and so on. Therefore, it is appropriate to retrofit the spacious factory building. As a multi-functional complex of culture and business, such as Jingdezhen Taoxichuan Ceramic Culture and Creative Park, the original site is Jingdezhen Cosmic Porcelain Factory, which covers various business hotel clubs, art design studios, featured commodity streets, multi-type restaurants, department stores, and public house, inn, leisure theater, etc., the total construction area of core area of universe porcelain factory is $180,000 \mathrm{~m} 2$, meanwhile emphasize public leisure area, fast food culture is set up around the area, light food is main, the idle saw factory building in the back hall has the potential for artistic transformation, make it as a design work workshop represented by the academic school, the front hall is used for reception and communication. For the macro transformation of the Changchun Tractor Manufactory, in 
particular, retain the original external features of the old factory building, highlight its style, and integrate modern design elements and have a strong sense of the times. In the end, a commercial center centered on ceramic culture is formed.

\subsection{Cultural Gallery}

The cultural gallery whose theme is industrial culture is constructed, including commerce, trade, industry and culture. The gallery shows its industrial flavor with its distinctive greenery, landscape, entertainment and culture. In this cultural gallery, industrial civilization is prominent, including the first diesel engine, the first tractor and other special value industrialized products, and show them, as well as statues of the technology and industry talents, the scene sculpture which Premier Zhou Enlai went to the Changchun Tractor Manufactory to inspect, work sculpture which Changchun Tractor Manufactory Party Secretary Li Shure, etc., the factory mainly by such exhibition, We can experience and continue the glory of Changchun's industrial civilization. The methods are mainly based on the industrial sculptures designed by industrial elements and old machine equipment, accompanied by landscape reconstruction, and maintains the historical print of the base station in the Changchun Tractor Factory.

\section{Conclusion}

The environment of industrial heritage has social, technical and aesthetic values, industrial heritage is a life record of an ordinary person in the social sense;, it is of great significance to the research of manufacturing history from technical and scientific angle, such as engineering and architecture; and from aesthetics, those striking buildings have their extraordinary aesthetic value and important aesthetic value of the layout. Therefore, we should correctly identify, protect, reuse and re-create industrial heritage and the environment.

This paper analyzes and discusses the protection and development of Changchun Tractor Manufactory by collecting relevant data and arranging it; various modes are envisaged for sustainable development, the feasibility of protection and utilization of some industrial heritages are proposed. The modern city under the background of urban renewal, more and more industrial heritages need to be protected and utilized in the future, the maintenance or removal of these potential old factories with industrial heritage features has become a major problem for us. Foreign industrialization process is relatively early, and there is a relatively complete theoretical system support, and we still need more references.

\section{References}

[1]. Xu Min. Discussion on Site Selection, Plan and Plane Layout of Artificial Beach in Coastal City [J]. Urban Roads Bridges \& Flood Control, 2017(08): 295-299+30.

[2]. Lin Humming. Comparison and Suggestions on the Beach Restoration Project of Fujian Day Ecological Demonstration Island [J]. Chinese \& Foreign Entrepreneurs, 2017(18): 136-137.

[3]. Mo Wei, Zhang Dian. Research on Landscape Renewal Model of Industrial Heritage Site in Kuancheng District of Changchun City under Urban Renewal[J].Sichuan Building Materials, 2017, 43(03): 52-53+92.

[4]. Xu Sunning, Wang Gouging, Li Sheen, Li Tao, Lb Zheng Hua, Liu Yan. Industrial Heritage Protection and Urban Renewal [J]. City Planning Review, 2017, 41(02): 81-84+101.

[5]. Zhang Kangsheng, He Wang, Hu Jingling, Liu Yu, Chen Rebio. Analysis on the Protection and Utilization of Industrial Heritage--Taking the Reconstruction of the Third-line Industrial Site of Chatoyant Factory Meaning as an Example [J]. Construction Science and Technology, 2015(12): 129- 132. 
[6]. Zhang Song. Conservation and Regeneration of Industrial Heritage Area in the Huangpu Riverside Redevelopment Process in Shanghai [J]. Urban Planning Forum, 2015(02): 102-109.

[7]. Li Shije, GAO Yankee. Preliminary Study of the Industrial Building Protection and Recycle of Changchun Tractor Plant [J]. Journal of Jilin Jinzhou University, 2014, 31(01):49-52.

[8]. Xu Dongfeng. Protection and Utilization of Chongqing Industrial Heritage and Urban Revitalization [D]. Chongqing University, 2012.

[9]. Zhang Jing. Research on the Protective Tourism Development of Industrial Heritage [D]. Shanghai Normal University, 2007.

[10]. Xing Huainan, Zhao Hengyang, Zhang Dejon. Value of Industrial Heritage and Its Conservation [J]. Journal of North-eastern University (Social Science), 2007(01): 16-19. 